inhalt $02 \cdot 2016$

editorial

3 ADK vermittelt aktuelles Wissen in Frankenthal

Auf zu neuen Ufern!

Matthias Herbst

top thema

8 Hirsutismus oft nicht erkannt

„Vielen Frauen kann man heute dauerhaft helfen“ Interview mit Hans Wolff

kongress

11 Tagung Dermatologische Praxis 2016

Ästhetische Dermatologie bildet wichtige Säule in Frankenthal

14 DDG-Kompakt in Leipzig

Die Haut im Alter

derma aktuell

16 Business Ethics - Wunscherfüller statt Heiler? Interview mit Keywan Taghetchian

26 Mikrofokussierter Ultraschall - Mit Hitze die Haut straffen

Interview mit Dr. Harald E. Petri

gastbeitrag

17 Silberstreif am Horizont

Neue Wirkstoffe in der Pipeline zur Behandlung der atopischen Dermatitis

Christine Bangert

22 Zurück zu den Tatsachen - was tun gegen unerwünschte Bewertungen?

Neue Rechtschutzmöglichkeiten gegen negative Bewertungen Felix Schiffner, Gwendolyn Gemke

cme fortbildung

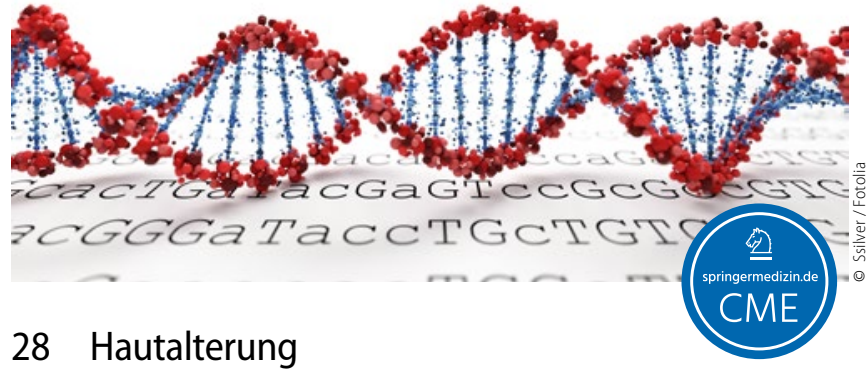

Molekulares Verständnis der ex- und intrinsischen Vorgänge

Evgenia Makrantonaki, Mona Vogel, Karin Scharffetter-Kochanek, Christos C. Zouboulis

\title{
34 CME-Fragebogen
}

praxis \& geld

\section{E-Health-Gesetz}

Jetzt die eigenen Möglichkeiten für digitale Medizin prüfen und planen

\section{Gesundheits-Apps}

Datei-Importe aus den Smartphones der Patienten mit Sicherheitsrisiken

\section{Arzthaftung}

Neue Wege im Prozessrecht bei Behandlungsfehlern gefordert

prisma

44 „Africa's Top Models“ in Hamburg begegnen Ideale Schönheit variiert in Ethnien

\section{Versuch einer Antwort in Bildern} Was ist Yoga?

rubriken

6 kurz \& knapp

41 infopharm

50 beirat

51 termine | impressum | kontakt

ADK

49 ADK-Beitrittsantrag

Pharma Report: Hyaluronidase: Adjuvans zur Unterstützung der Lokalanästhesie (Seite 47) 